\title{
Cigarette smoking and asthma: A dangerous mix
}

\author{
Catherine Lemiere MD MSc ${ }^{1}$, Louis-Philippe Boulet MD FRCPC ${ }^{2}$
}

C Lemiere, L-P Boulet. Cigarette smoking and asthma: A dangerous mix. Can Respir J 2005;12(2):79-80.

In Canada, $20 \%$ to $30 \%$ of the general population currently smoke. Smoking is as common in those suffering from asthma as it is in the general population. However, most studies on the pathophysiology of asthma and its response to treatment only include nonsmokers. Available data that examine the influence of smoking on clinical, functional and inflammatory characteristics of asthma, as well as the influence of smoking on the therapeutic response to corticosteroids, were reviewed. Active smoking is associated with an increased morbidity from asthma and impairs the response to inhaled corticosteroids. These observations emphasize the need for smoking cessation in patients with asthma and for reassessment of current treatment guidelines in this population.

Key Words: Airway inflammation; Asthma; Corticosteroids; Smoking

\section{Le tabagisme et l'asthme : Un mélange dangereux}

Au Canada, de $20 \%$ à $30 \%$ de la population générale fume. Le tabagisme est tout aussi courant chez les asthmatiques que dans le reste de la population. Cependant, la plupart des études sur la physiopathologie de l'asthme et sa réponse au traitement incluent seulement les non-fumeurs. Les données disponibles qui portent sur l'influence du tabagisme sur les caractéristiques cliniques, fonctionnelles et inflammatoires de l'asthme, de même que sur l'influence du tabagisme sur la réponse thérapeutique aux corticoïdes, ont été analysées. Le tabagisme actif s'associe à une augmentation de la morbidité causée par l'asthme et nuit à la réponse aux corticoïdes en aérosol. Ces observations font ressortir la nécessité que les asthmatiques arrêtent de fumer et le besoin de réévaluer les directives courantes sur le traitement de cette population.
W orldwide, the use of tobacco is associated with the death of up to one in 10 adults (1). The leading causes of tobacco-related deaths are coronary artery disease and stroke. Chronic obstructive pulmonary disease (COPD) is in sixth place and is likely to move up the list in the future (2). In 1995 , it was estimated that $29 \%$ of people 15 years of age and older were regular smokers (3). The latest Canadian estimate, from 2001, suggests that between $20 \%$ and $30 \%$ of the population are active smokers (4).

It is generally accepted that smoking can not only cause some respiratory diseases such as COPD, but can also worsen others, such as asthma. However, studies investigating the pathophysiology of asthma or the effect of different drugs on asthma are usually performed with nonsmoking asthmatics to avoid potential bias. In Canada, active smoking is as frequent in asthmatic subjects as in the general population (Figure 1). Because up to one-third of asthmatics are current smokers (5), a substantial proportion of the asthmatic population is, thus, excluded from these studies. Therefore, the effect of smoking on the clinical expression of asthma and its response to therapy has not been properly assessed for many years, and it is possible that current treatment guidelines may not strictly apply to asthmatic patients who smoke.

\section{SMOKING AND AIRWAY INFLAMMATION}

Several studies have described the effects of smoking on airway inflammation in subjects without asthma or COPD. Bosken et al (6) analyzed lung tissue from 20 patients undergoing resection for a peripheral lung carcinoma. They showed that the number of submucosal neutrophils was directly proportional to tobacco consumption.

Lams et al (7) investigated the effect of smoking on small airway submucosal immunopathology. They obtained peripheral lung sections from two groups: smokers and nonsmokers (the latter included both exsmokers and lifelong nonsmokers). They found an increase in the number of total and activated eosinophils in the small airway submucosa from smokers compared with nonsmokers. There was also an increase in neutrophils from smokers compared with lifelong nonsmokers. These changes were proportional to the duration of smoking.

\section{INFLUENCE OF SMOKING ON ASTHMA: CLINICAL EXPRESSION, PULMONARY FUNCTION AND AIRWAY INFLAMMATION}

There is increasing evidence that smoking is detrimental to asthmatic patients in many ways, affecting both functional and inflammatory parameters, and resulting in increased asthma severity.

Although smoking is not a significant risk factor for adulthood asthma, it does seem to increase the severity of asthma (8). Indeed, in a subanalysis of the Epidemiological Study on the Genetics and Environment of Asthma (EGEA) study, Siroux et al (8) showed a statistically significant relationship between smoking and asthma severity score.

${ }^{1}$ Department of Chest Medicine, Hôpital du Sacré-Coeur, Montreal; ${ }^{2}$ Institut de cardiologie et de pneumologie de l'Université Laval, Hôpital Laval, Quebec City, Quebec

Correspondence: Dr Catherine Lemiere, Department of Chest Medicine, Sacré-Coeur Hospital, 5400 West Gouin, Montreal, Quebec H4J 1C5.

Telephone 514-338-2796, fax 514-338-3123, e-mail lemierec@crhsc.umontreal.ca 


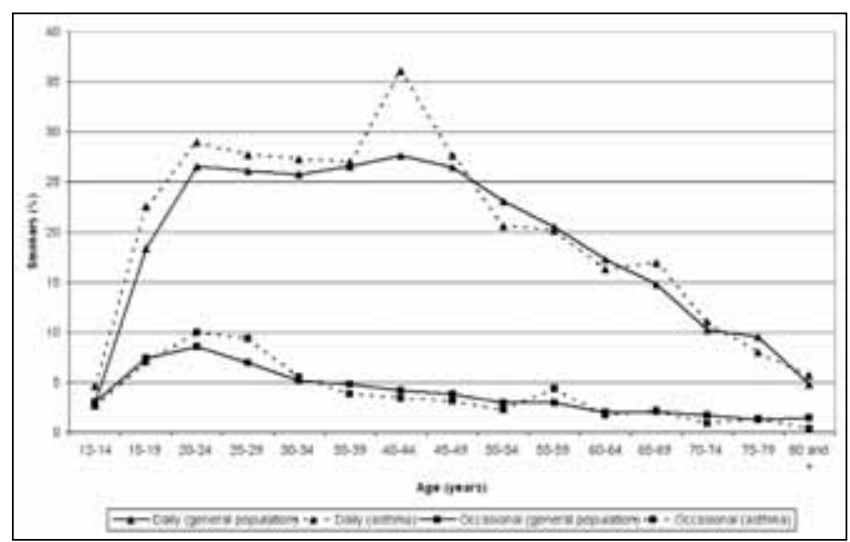

Figure 1) Prevalence of smoking in the general and asthmatic population in Canada. Triangles correspond to daily smoking whereas squares correspond to occasional smoking. Dotted lines represent asthmatic subjects and full lines represent the general population. This figure has been produced from anonymous data obtained from the Statistics Canada public microdata files of the Canadian Community Health Survey Cycle 1.1 (2000-2001)(16). The analysis and interpretation of these microdata are under the sole responsibility of the authors

Furthermore, Lange et al (9) described an accelerated decline of respiratory function (forced expiratory volume in $1 \mathrm{~s}$ ) in asthmatic compared with nonasthmatic populations, and asthmatic patients who smoke fared worse than the nonsmoking patients (9).

Smoking seems to alter the immunological response differently in healthy and asthmatic subjects. Sunyer et al (10) investigated the extent to which smoking modified the effect of asthma on circulating eosinophils, CD4+ and CD8+ T cell counts. They examined 1420 blood samples from 197 asthmatic and 15,822 samples from 1997 nonasthmatic patients. Smoking increased eosinophils in nonasthmatics, but not in those with asthma. In contrast, no differences in peripheral blood $\mathrm{T}$ cell counts were observed between the two groups.

\section{THERAPEUTIC RESPONSE TO} CORTICOSTEROIDS IN ASTHMATIC SMOKERS

The way smoking may modify airway inflammation in asthmatic subjects could influence their response to asthma treatment. Indeed, the response to asthma medications, and more specifically, to inhaled or oral corticosteroids, seems to be reduced in asthmatic smokers compared with asthmatic nonsmokers.

In an open study, Pedersen et al (11) randomized 85 allergic and nonallergic asthmatic subjects into three groups. They received high-dose inhaled budesonide, low-dose inhaled budesonide or oral theophylline, and were followed for 11 months with lung function testing and blood sampling for measurements of serum eosinophil and neutrophil markers. There was an improvement in lung function and a reduction of eosinophil markers, but only in nonsmoking asthmatic patients, whereas neither lung function nor eosinophil markers changed in smokers, even with high-dose budesonide. More recently, a doubleblind, prospective, randomized, placebo-controlled study of 38 steroid-naive, adult asthmatic patients (12), 21 of whom were nonsmokers, assessed the effects of smoking on the response to inhaled corticosteroid treatment. Nonsmokers had a reduction in sputum eosinophils after corticosteroid treatment compared with those receiving placebo, but this was not observed in asthmatic patients who smoke. In accordance with these data, a randomized, placebo-controlled, cross-over study
(13) showed that there was a significant improvement in asthma symptoms and in pulmonary function after a trial of $40 \mathrm{mg}$ of oral prednisolone in asthmatics who had never smoked, whereas a similar improvement was not observed in asthmatic smokers.

The mechanisms of corticosteroid 'resistance' in asthmatic patients who smoke should be further studied (14). This may be traceable to factors such as different types or severity of underlying airway inflammation, or to mechanisms such as decreased histone deacetylase activity from smoking, which could influence the suppressor effect of corticosteroids on cytokine induction (15).

\section{CONCLUSION}

Active smoking is surprisingly as frequent in asthmatic patients as in the general population. It is associated with increased morbidity from asthma and impairs the response to inhaled or oral corticosteroids in these subjects. Recent studies further emphasize the importance of smoking cessation in asthma. Research should be done to determine the best therapeutic approach for asthmatic patients who smoke.

FUNDING: Dr Lemiere holds a scholarship from the Canadian Institutes of Health Research.

\section{REFERENCES}

1. Loddenkemper R, Sybrecht GW. Health care costs of smoking. Eur Respir J 2000;16:377-8.

2. Murray CJ, Lopez AD. Mortality by cause for eight regions of the world: Global Burden of Disease Study. Lancet 1997;349:1269-76

3. Jha P, Ranson MK, Nguyen SN, Yach D. Estimates of global and regional smoking prevalence in 1995, by age and sex. Am J Public Health 2002;92:1002-6.

4. Health Canada. Respiratory Disease in Canada. Ottawa: Canadian Lung Association, 2001.

5. Althuis MD, Sexton M, Prybylski D. Cigarette smoking and asthma symptom severity among adult asthmatics. J Asthma 1999;36:257-64.

6. Bosken $\mathrm{CH}$, Hards J, Gatter K, Hogg JC. Characterization of the inflammatory reaction in the peripheral airways of cigarette smokers using immunocytochemistry. Am Rev Respir Dis 1992;145:911-7.

7. Lams BE, Sousa AR, Rees PJ, Lee TH. Immunopathology of the smallairway submucosa in smokers with and without chronic obstructive pulmonary disease. Am J Respir Crit Care Med 1998;158:1518-23.

8. Siroux V, Pin I, Oryszczyn MP, Le Moual N, Kauffmann F. Relationships of active smoking to asthma and asthma severity in the EGEA study. Epidemiological study on the Genetics and Environment of Asthma. Eur Respir J 2000;15:470-7.

9. Lange P, Parner J, Vestbo J, Schnohr P, Jensen G. A 15-year follow-up study of ventilatory function in adults with asthma. N Engl J Med 1998;339:1194-200.

10. Sunyer J, Springer G, Jamieson B, et al. Effects of asthma on cell components in peripheral blood among smokers and non-smokers. Clin Exp Allergy 2003;33:1500-5.

11. Pedersen B, Dahl R, Karlstrom R, Peterson CG, Venge P. Eosinophil and neutrophil activity in asthma in a one-year trial with inhaled budesonide. The impact of smoking. Am J Respir Crit Care Med 1996;153:1519-29.

12. Chalmers GW, Macleod KJ, Little SA, Thomson LJ, McSharry CP, Thomson NC. Influence of cigarette smoking on inhaled corticosteroid treatment in mild asthma. Thorax 2002;57:226-30.

13. Chaudhuri R, Livingston E, McMahon AD, Thomson L, Borland W, Thomson NC. Cigarette smoking impairs the therapeutic response to oral corticosteroids in chronic asthma. Am J Respir Crit Care Med 2003;168:1308-11.

14. Thomson NC, Chaudhuri R, Livingston E. Active cigarette smoking and asthma. Clin Exp Allergy 2003;33:1471-5.

15. Ito K, Lim S, Caramori G, Chung KF, Barnes PJ, Adcock IM. Cigarette smoking reduces histone deacetylase 2 expression, enhances cytokine expression and inhibits glucocorticoid actions in alveolar macrophages. FASEB J 2001;15:1110-2.

16. Statistics Canada. Canadian Community Health Survey (CCHS) Cycle 1.1. < www.statcan.ca/english/concepts/health/> (Version current at November 18, 2004) 


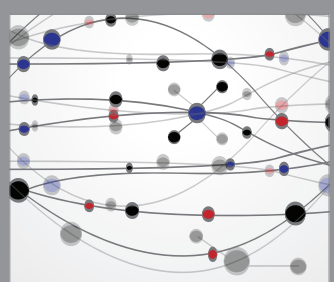

The Scientific World Journal
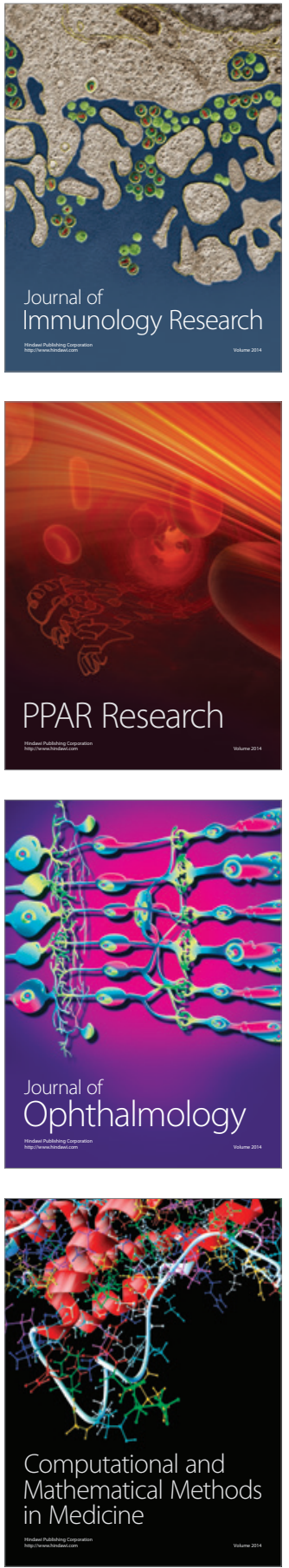

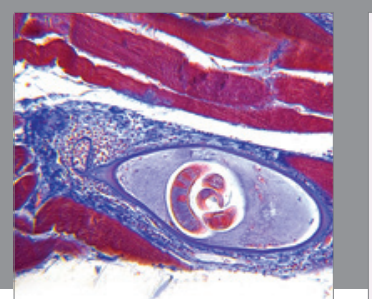

Gastroenterology Research and Practice

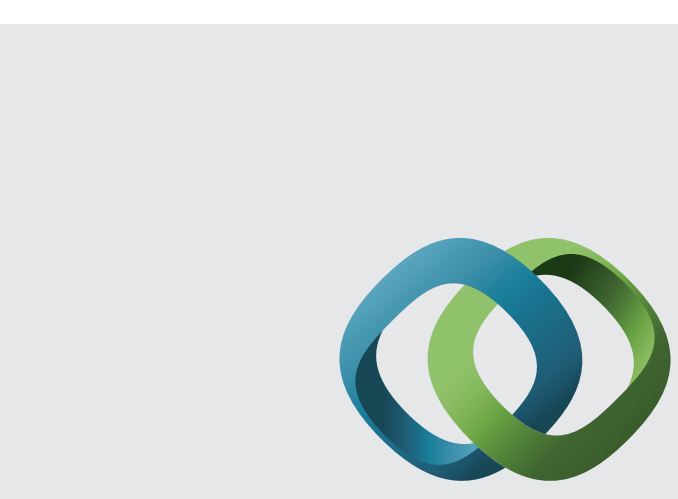

\section{Hindawi}

Submit your manuscripts at

http://www.hindawi.com
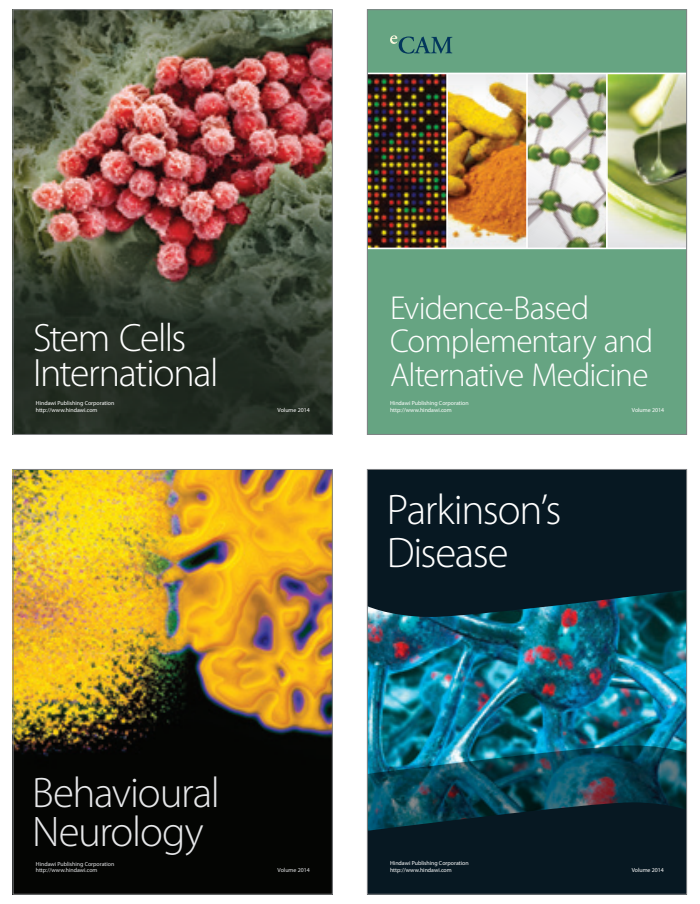
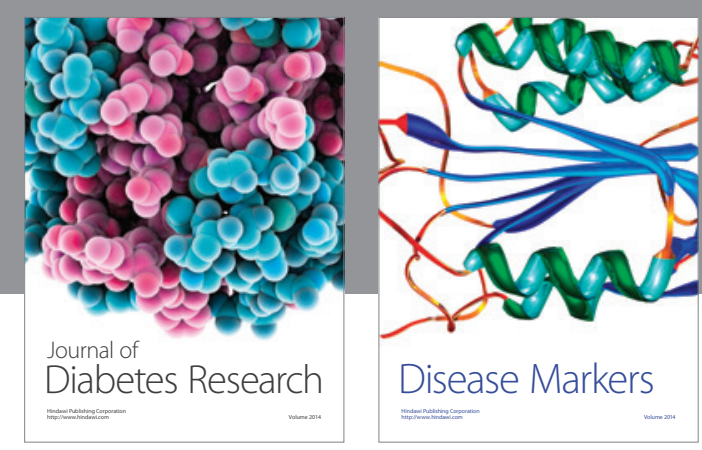

Disease Markers
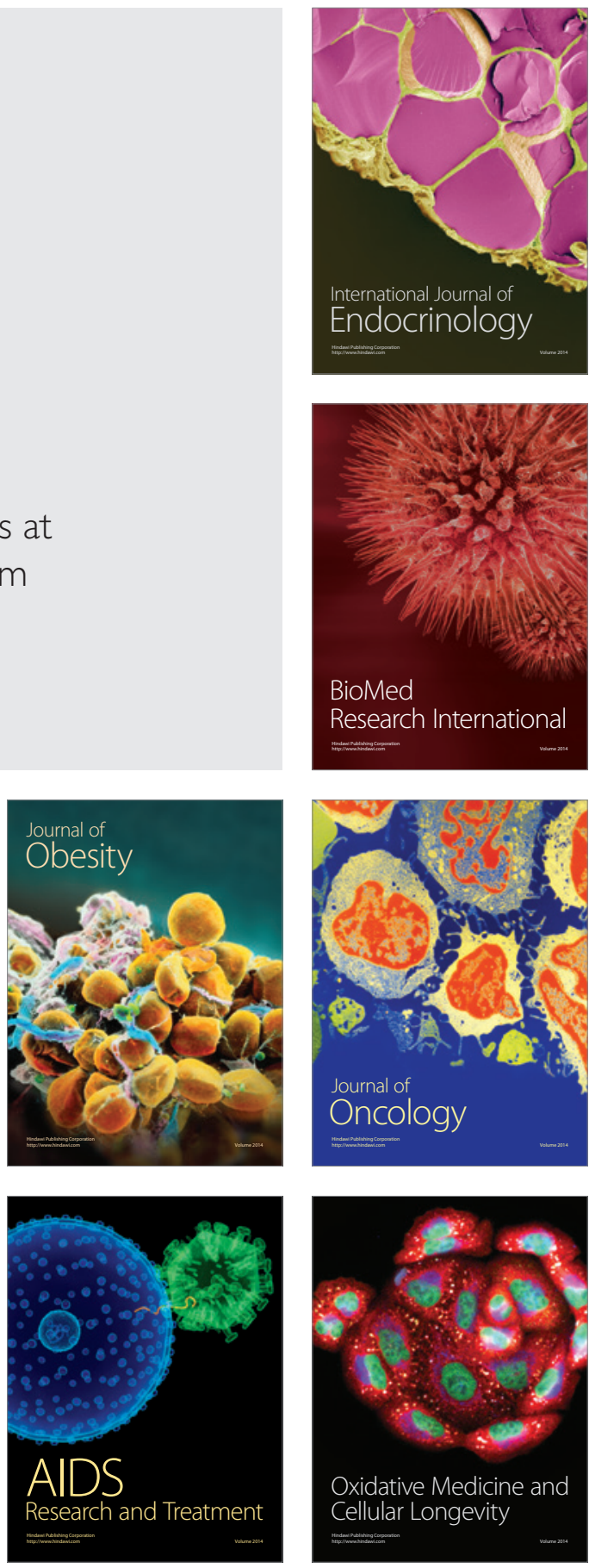